\title{
3, 2, 1 gravando! e agora? simulação de aula no processo de formação inicial de professores de Química
}

Aléxia Birck Fröhlich*, Fabiane de Andrade Leite ${ }^{\star *}$

\section{Resumo}

As práticas de ensino são componentes curriculares obrigatórios nos cursos de licenciatura no Brasil e têm sido objeto de estudo no decorrer dos últimos anos, em que se busca qualificar os processos de formação de professores. Tendo como objetivo investigar as contribuições de uma metodologia diferenciada realizada em aulas de práticas de ensino, desenvolvida em um curso de licenciatura em Química de uma universidade pública, realizou-se este estudo, que apresenta as possibilidades formativas de uma atividade de simulação de aula. A atividade de simulação teve como intenção proporcionar, aos futuros professores, experiências reais da vivência em sala de aula antes da realização do estágio curricular e, ainda, a compreensão dos desafios e possibilidades do planejamento de ensino e da execução em sala de aula. Por meio do relato de uma licencianda, participante da atividade, em seu diário de bordo, um instrumento utilizado como registro de reflexão pessoal, identificou-se o desenvolvimento de entendimentos acerca das características reais da sala de aula, tais como tempo de aula, interação professor-aluno e a vivência de situações inesperadas de ensino. Destaca-se que a experiência vivenciada, por meio do processo de simulação de aula, qualificou o processo formativo por meio do desenvolvimento de saberes experienciais.

Palavras-chave: Experiência docente. Formação inicial. Prática de Ensino.

* Acadêmica do curso de Química Licenciatura da Universidade Federal da Fronteira Sul (UFFS) - Campus Cerro Largo/RS, Brasil. E-mail: alexia.b.f10@gmail.com

* Doutora em Educação nas Ciências. Mestre em Ensino Científico e Tecnológico. Professora de Práticas de Ensino e Estágio Supervisionado do curso de Química Licenciatura (UFFS) - Campus Cerro Largo/RS, Brasil. E-mail: fabianeandradeleite@gmail.com

Recebido em: 02/12/2019 - Aceito em: 23/03/2020

https://doi.org/10.5335/rbecm.v3i1.10309

http://creativecommons.org/licenses/by-nc-nd/4.0 


\section{Introdução}

A formação inicial de professores tem sido temática de discussão recorrente nos espaços que buscam qualificar os processos de ensino no Brasil ao longo dos últimos 20 anos. De forma especial, as discussões têm se intensificado a partir da aprovação das diretrizes curriculares nacionais para a formação de professores em 2015, por meio da Resolução 2/2015, do Conselho Nacional de Educação. A resolução define que os cursos de formação inicial de professores devem ofertar 400 horas de práticas de ensino como componente curricular, além das demais disciplinas específicas, bem como os estágios supervisionados. De acordo com a resolução:

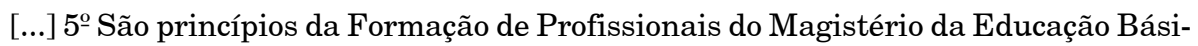
ca: [...] V - a articulação entre a teoria e a prática no processo de formação docente, fundada no domínio dos conhecimentos científicos e didáticos, contemplando a indissociabilidade entre ensino, pesquisa e extensão (BRASIL, 2015, p. 4).

Em nossas vivências formativas temos compartilhado ações desenvolvidas em turmas de práticas de ensino em um curso de Licenciatura em Química de uma universidade pública do interior do estado do Rio Grande do Sul (RS). Nesse contexto, buscamos atentar para aspectos metodológicos que contribuem ao processo formativo de maneira mais qualificada, com o objetivo de promover maior articulação entre a teoria e a prática no processo de formação docente (BRASIL, 2015, p. 4). Assim, apresentamos neste texto reflexões que emergiram da realização de uma atividade de simulação de aula, proporcionada no componente curricular de Metodologia do Ensino de Ciências e Química, que é ofertado na quarta fase do curso, antes da realização dos estágios supervisionados.

A realização da atividade de simulação de uma sala de aula teve como objetivo contribuir para que os licenciandos desenvolvessem um olhar crítico para o processo de atuação docente e, ainda, tivessem a oportunidade de maior aproximação com as situações reais de sala de aula. Para tanto, cada licenciando deveria planejar e executar uma aula de 45 minutos aos próprios colegas, sendo que a aula seria filmada e posteriormente analisada pelo próprio licenciando. Cabe destacar que o principal aspecto a ser analisado na atividade foram as reflexões dos licenciandos após olharem as filmagens de suas próprias aulas, o que nos levou ao questionamento: Que contribuições a simulação de uma aula pode proporcionar aos futuros professores de Ciências/Química? 
Partimos da compreensão que a reflexão da prática contribui ao processo formativo, conforme propõe Nóvoa (1995). Para o autor, “[...] a formação não se constrói por acumulação (de cursos, conhecimentos ou de técnicas), mas sim através de um trabalho de reflexividade crítica sobre as práticas e de (re)construção permanente de uma identidade pessoal" (NÓVOA, 1995, p. 25). Sob essa perspectiva, atentamos para a formação do professor reflexivo, corroborando as ideias de Alarcão (2005), Schön (1995) e Zeichner (1993), que convergem com o pensamento do profissional que reflete na ação e para a ação.

Dessa forma, temos proporcionado vivências formativas que se tornam experiências docentes aos licenciandos, pois, conforme propõe Larrosa (2002), é na experiência que vamos nos tornando professores, experiências de leitura, de práticas, de vida. Para o autor,

Em qualquer caso, seja como território de passagem, seja como lugar de chegada ou como espaço do acontecer, o sujeito da experiência se define não por sua atividade, mas por sua passividade, por sua receptividade, por sua disponibilidade, por sua abertura. Trata-se, porém, de uma passividade anterior à oposição entre ativo e passivo, de uma passividade feita de paixão, de padecimento, de paciência, de atenção, como uma receptividade primeira, como uma disponibilidade fundamental, como uma abertura essencial (LARROSA, 2002, p. 24).

Proporcionar vivências de atuação profissional aos futuros professores tornou-se o foco de nossas intenções formativas nas práticas de ensino que temos compartilhado. No contexto de formação inicial, empreendemos esforços em proporcionar ações que possibilitem reflexão permanente dos licenciandos a fim de possibilitar o desenvolvimento de entendimentos acerca da produção de conhecimentos a partir da prática docente. Tal perspectiva é apresentada por Zeichner (1993, p. 16), ao afirmar que,

Reflexão também significa o reconhecimento de que a produção de conhecimento sobre o que um ensino de qualidade não é propriedade exclusiva das universidades e centros de investigação e desenvolvimento e de que os professores também têm teorias que podem contribuir para uma base codificada de conhecimentos de ensino.

Nesse sentido, temos observado a valorização de metodologias que proporcionam experiências formativas ao longo da formação inicial do professor. Em nossas vivências identificamos a inserção dos licenciandos em ações que buscam qualificar o processo formativo por meio de experiências que aproximam universidade e escola, tais como PIBID (Programa Institucional de Bolsas de Iniciação Científica), PET (Programa de Educação Tutorial), Residência Pedagógica, estágios curriculares e 
práticas de ensino. Todas essas ações reforçam e qualificam a constituição do professor. Porém, nem todos os alunos dos cursos de licenciatura têm a oportunidade de vivenciar as ações em tais programas. Assim, cabe ao professor formador promover situações que potencializem aspectos que poderão ser vivenciados em sala de aula.

Com essas compreensões, apresentamos na sequência o contexto da experiência vivida e as reflexões realizadas por uma licencianda do curso, participante do processo de simulação.

\section{Contexto da experiência vivenciada}

O contexto do presente relato é a atividade de simulação de uma aula desenvolvida em uma turma de nove licenciandos do curso de Química Licenciatura de uma universidade pública no RS, no componente curricular regular (CCR) de Metodologia e Didática do Ensino de Ciências e Química, no segundo semestre de 2018. A disciplina é ofertada na $4^{\mathrm{a}}$ Fase do curso, realizada antes dos estágios curriculares, é organizada em 60 horas-aula e busca "promover espaços da discussão sobre o ensino de Química e de Ciências considerando as particularidades das metodologias de ensino, do planejamento e da avaliação" (UFFS, 2012, p. 83).

Cabe destacar, que ao longo das aulas foram apresentadas diversas metodologias, leituras e discussões de artigos acerca de como planejar uma aula, a importância dos objetivos e metodologias realizadas. Assim, no início do semestre, a professora responsável do CCR apresentou a proposta de realização de uma simulação de aula por licenciando. Na proposta, cada licenciando deveria elaborar um plano de ensino de um determinado conteúdo (sendo que a série poderia ser escolhida pelo licenciando), na sequência e, após a análise da professora responsável, os planos seriam executados em um período de 30 minutos na sala de aula, momento em que a aula seria gravada com recurso de áudio e vídeo. Ainda, os demais licenciandos deveriam participar do processo na condição de aluno da respectiva série a qual o plano foi elaborado.

Todos concordaram com a atividade, que foi realizada durante as aulas ao final do semestre, após todo o processo de construção e análise de planejamento de ensino ter sido finalizado. Considerando que o número de licenciandos matriculados era de nove, a atividade foi realizada em quatro turnos diferentes, sendo um para a discussão do plano de ensino e possíveis ajustes, e outros três turnos para a realização da 
simulação e as gravações da aula. Nos três turnos da simulação, três licenciandos eram responsáveis em ministrar a aula planejada.

Assim, no presente relato discorremos aspectos de formação que marcaram a vivência formativa, sendo a elaboração e realização da simulação e a perspectiva formativa de uma licencianda para a gravação realizada, tendo como foco as contribuições para a formação inicial de futuros professores de Ciências e Química e, também, o potencial da atividade no processo de reflexão da prática docente, por meio do diário de bordo, que, na visão de Porlán e Martin (1997), se constitui como um espaço que possibilita o movimento de reflexão para com a própria prática docente, caracterizando o sujeito em formação como um professor pesquisador.

Cabe destacar que o processo das escolhas das temáticas foi muito esperado pelos licenciandos, tendo em vista a construção do primeiro planejamento de ensino por cada um. Tomamos como exemplo a primeira temática, que permitiu a todos entender a evolução da matéria e como esta se adaptou através de modificações realizadas por ações humanas ao longo dos anos, reforçando que a Ciência não é imutável.

Como a tarefa era individual, os temas foram escolhidos e distribuídos pela professora responsável, e contemplaram conteúdos tanto para aulas de Ciências no ensino fundamental quanto de Química para o ensino médio, de acordo com o que está apresentado no Quadro 1. Destacamos que, para facilitar a discussão e preservar o anonimato dos participantes, os licenciandos estão identificados por L1, L2, e assim sucessivamente.

Quadro 1: Temáticas que cada licenciando (a) utilizou para a construção do planejamento

\begin{tabular}{|l|l|l|}
\hline \multicolumn{1}{|c|}{ Licenciandos } & \multicolumn{1}{|c|}{ Série/ Nível de Ensino } & \multicolumn{1}{c|}{ Temática/Conteúdo } \\
\hline L1 & $9^{\circ}$ Ano - Ensino Fundamental & História da Constituição da Matéria \\
\hline L2 & $2^{\circ}$ Ano - Ensino Médio & $\begin{array}{l}\text { Fatores que Influenciam na Velocidade das } \\
\text { Reações Químicas }\end{array}$ \\
\hline L3 & $1^{\circ}$ Ano - Ensino Médio & História dos Modelos Atômicos \\
\hline L4 & $3^{\circ}$ Ano - Ensino Médio & Produção de Petróleo e Derivados \\
\hline L5 & $1^{\circ}$ Ano - Ensino Médio & Introdução às Ligações Químicas \\
\hline L6 & $3^{\circ}$ Ano - Ensino Médio & Funções Orgânicas Oxigenadas \\
\hline L7 & $6^{\circ}$ Ano - Ensino Fundamental & Forma, Estrutura e Movimentos da Terra \\
\hline L8 & $1^{\circ}$ Ano - Ensino Médio & Forças Intermoleculares \\
\hline L9 & $1^{\circ}$ Ano - Ensino Médio & Identificação de Ácidos e Bases \\
\hline
\end{tabular}

Fonte: Autoras. 
Com as temáticas escolhidas, observamos muito envolvimento dos licenciandos na elaboração dos planejamentos, nas orientações da professora, na busca de atividades a serem realizadas, na construção de objetivos, sem falar na expectativa do dia da simulação, que gerou em todos nervosismo.

O estudo das contribuições da atividade de simulação para o processo de formação dos futuros professores ocorreu a partir da análise de escrita reflexiva de uma licencianda (L1), participante da atividade, que esteve presente em todos os momentos, desde a escolha da temática, realização do planejamento, orientação com a professora formadora e, ainda, se envolveu com a apresentação da simulação dos demais colegas. As reflexões escritas foram realizadas por ela no diário de bordo, um dos instrumentos utilizados no curso, que tem contribuído significativamente no processo de formação inicial de professores na universidade. A utilização do diário de bordo como instrumento formativo no curso tem contribuído no processo de reflexão pelos futuros professores.

Para a escrita nos diários de bordo, os licenciandos são desafiados a relatar as experiências vividas e expressar as sensações que tiveram na participação das atividades, ainda devem elaborar um título da reflexão, o que os faz pensar acerca do foco do trabalho realizado. Na sequência, recortamos duas partes do diário de L1, sendo a primeira em que a licencianda reflete acerca da sua formação e a segunda em que ela analisa o papel de colegas que contribuem na constituição docente.

\section{Eu, professora!!}

A sala de aula é o palco do professor, e é onde quero passar meus dias a fazer o que mais gosto: ensinar. Não é preciso dançar conforme a música, pois cada docente é singular e é desta forma que apresento neste relato a nossa experiência e reflexão sobre uma simulação de aula visando à postura e a forma de conduzir uma aula, controlando o tempo e o espaço que nos foi dado, não apenas de forma individual, mas escrevendo críticas construtivas e participando da aula do colega, que por um momento foi o professor.

Preciso admitir que gostei muito da temática que me foi atribuída para o planejamento, muito mesmo! Aprendi coisas que nunca passariam pela minha cabeça, espero que eu tenha conseguido passar este meu entusiasmo para os meus "alunos", pois só tenho a agradecer por este momento vivido. Afinal, a História da Consti- 
tuição da Matéria não é algo que se aprende em um ponto de ônibus com amigos em uma conversa informal; é um conteúdo específico que requer conhecimentos científicos que envolveram anos de estudos dos cientistas. E, sim, precisei pensar em tudo o que ia falar com muito cuidado, para que não passasse para os alunos alguma informação equivocada.

Como nenhum plano de ensino é perfeito, após a primeira elaboração do plano de aula observei que todos meus colegas voltaram com contribuições da professora, que deveriam ser feitas, inclusive eu, e não foram poucas, pois sempre há o que se pode ser melhorado. Utilizo muito meu diário de bordo, tanto como bolsista no PET Ciências, quanto nas aulas, pois, com esse tipo de escrita, posso registrar as experiências vividas ao longo do curso e compará-las posteriormente, a fim de identificar meu progresso, como ser humano e também como futura professora.

Acredito que para a professora responsável, assim como das outras vezes em que ela ministrou esta prática, deixar de lado o papel principal em sala de aula, para se tornar uma singela espectadora, não foi tarefa fácil. Os responsáveis pela análise das simulações, e meus alunos na aula, eram meus próprios colegas, pessoas com quem convivo desde o começo do curso. Lendo o que estou escrevendo, até parece que tudo foi fácil; pelo contrário, não foi. Posso afirmar que participar da atividade possibilitou conhecer minhas potencialidades e dificuldades em situações inesperadas, porque é assim que caracterizo uma sala de aula. Você pensa em tanta coisa a ser feita, mas, na hora, a realidade é bem diferente. Mas chega de conversa, pois com o prazo esgotado, filmadora na mão e tudo dentro dos conformes, chegou o grande dia...LUZ, CÂMERA, AÇÃO! E agora?

Experiências como esta me proporcionaram momentos profundos de reflexão, tanto como futura professora, quanto em relação aos meus colegas. Por estar em um curso de licenciatura, destaco a importância de práticas como esta, para mostrar o que pode ser melhorado e tirar um pouco da insegurança referente à educação básica. O esforço que faço enquanto licencianda irá se estender, com certeza, mas no momento preciso focar acerca da minha prática pedagógica sempre, é claro, com o apoio de um(a) professor(a), pois, conforme Maldaner (2003) todos aprendem e todos ensinam e também se colocam como um espaço de interação entre a formação inicial e continuada.

Com esse trabalho, ficou claro que a docência não é um "mar de rosas", enfrentarei dificuldades e vários obstáculos que farão eu me perguntar: é isto mesmo que 
eu quero? O importante é nunca desistir, principalmente um professor, que é um exemplo para seus alunos, e eles devem sentir isso. Bom, posso afirmar que foi através dessa simulação que senti o reconhecimento dos meus colegas, elogiando-me em relação ao domínio do conteúdo apresentado. Em alguns momentos eu pude sentir isso em vários deles também, que eles foram, sim, professores, deixando de lado a timidez e o nervosismo que a vivência ao longo do curso me mostrou, e eu fiquei simplesmente encantada. Porém, preciso dizer algo que me tocou na atividade, a pergunta da professora responsável: após olhar teu vídeo, tua aula, quero que me diga em que momento, ou momentos, você se viu como professora?

Bom, estar na frente de uma câmera pode ser uma experiência bem angustiante para alguns, porque todos os seus movimentos e falas estão sendo gravados. Mas, para que essa atividade funcionasse, a gravação era necessária, pois cada licenciando recebeu seu vídeo para que depois pudesse escrever sobre os pontos positivos e também os negativos, como autocrítica. Sobre a minha aula, como já citado, preparei com muita informação, embasada em um conhecimento científico com o auxílio do livro didático do respectivo ano. $\mathrm{O}$ ato de ensinar, não importa se o professor está iniciando sua carreira docente ou já a tem estabelecida há anos, sempre nos dá um frio na barriga e o nervosismo, com certeza, aparece, por mais que tentamos controlá-lo. Assistindo ao meu vídeo várias e várias vezes e partindo também de alguns comentários dos meus próprios colegas, eu pensei: NOSSA, EU REALMENTE SOU UMA PROFESSORA. Se existe algo mais maravilhoso do que saber que você está no curso certo, no caminho certo, fazendo o que ama e sendo reconhecida por isso, desconheço. Perceber o olhar atento do aluno, sua concentração em aula para fazer o que foi passado e a sua curiosidade em aprender, são coisas que dinheiro nenhum pode comprar.

\section{Meus colegas, professores!}

No que se refere aos meus colegas como professores, creio que todos foram bem, mesmo dentro de suas limitações. Algo que todos precisamos aprender é, também, se autoavaliar e fazer uma crítica positiva/reflexiva, o que não é tarefa fácil. Como nos conhecemos desde o primeiro semestre do curso, fiquei admirada com a evolução de alguns colegas, em momentos que a timidez foi deixada de lado e ali eu vi realmente um(a) professor(a). Dedicação também não faltou para ninguém, tanto 
nos planos de ensino quanto nas simulações, pois esta atividade só foi possível com a colaboração de todos.

Fui uma das poucas que não trouxeram algum tipo de experimento, ou seja, fiquei apenas na teoria, por assim dizer. Mas, o que eu poderia trazer, sendo que no meu planejamento dizia que era a primeira aula de Química para o 9o Ano do Ensino Fundamental? Optei pela teoria e pela história da Ciência e não me arrependo, pois o que vi nas aulas de alguns colegas foram apenas experimentos. Meus colegas deram muita ênfase a prática e nada ao conceito, tivemos que adivinhar, ao final, sobre o quê a aula estava tratando.

Já em matéria de nervosismo, quem nunca se sentiu assim, ainda mais em uma simulação. Pude observar certa insegurança também, alguns colegas estavam muito nervosos, acho que foi em função do conteúdo não ser tão simples, tendo muita leitura nos slides e o tom de voz estava abaixo do ideal. Ainda, percebi que outros colegas tinham domínio sobre o conteúdo, porém olhavam bastante para a câmera, parecendo estarem um pouco perdidos com o tempo e divagavam em alguns momentos. De todas as aulas dadas pude perceber maior segurança em dois colegas, o domínio do conteúdo e a confiança no que estavam propondo.

E, por fim, eu, como me vi na filmagem? Primeiramente, preciso dizer o quão complicado foi montar o plano de ensino que deu vida à simulação, pois tudo devia estar bem detalhado, sem contar os imprevistos que podem ocorrer em uma sala de aula. Tive como embasamento um livro didático da respectiva série e gostei muito do assunto, várias foram as alterações feitas até tudo estar em ordem, sem nunca esquecer que o plano perfeito não existe, e que uma aula de qualidade é de responsabilidade do professor. Não mudaria nada em termos de conteúdo a ser ensinado, mas acrescentaria, pois na hora de estar na frente da câmera e dos alunos, esqueci algumas coisinhas, mas o jogo segue. Levei um grande susto quando a professora disse que ia nos gravar, e isso só piorou quando vi minha simulação, mas creio que me saí bem, olhei pouco para a câmera e consegui olhar nos olhos dos meus alunos durante a aula, questionando-os sempre que necessário. Isto só reforçou que o professor não é dono da razão ou o senhor de todo o conhecimento, o que faz um professor é o estudo diário e como lidar com as perguntas e os pormenores que acontecem no ambiente escolar. Uma coisa ficou clara para mim: o trabalho do professor é muito complexo e exige muito planejamento! 


\section{Discussão das reflexões}

A atividade de simulação, realizada na aula de prática de ensino no curso de licenciatura em Química, proporcionou entendimentos acerca de aspectos significativos na formação dos futuros professores. Tais aspectos foram evidenciados nos diários dos licenciandos e na própria vivência dos momentos em que a atividade transcorreu.

No momento vivenciado em sala de aula, durante as gravações de aulas, as atitudes e posturas dos licenciandos possibilitaram identificarmos escolhas e decisões tomadas pelos futuros professores, in loco. Tais escolhas contribuíram para que pudéssemos compreender aspectos que seriam evidenciados apenas durante a realização dos estágios curriculares supervisionados, entre os quais destacamos estratégias utilizadas, condução de atividades em sala de aula. Assim, como formadores, a atividade de simulação contribuiu para nos prepararmos ao processo de orientação de estágios e demais ações a serem realizadas ao longo do curso.

Ainda, destacamos o sentimento de colaboração entre os colegas na realização da gravação: uns ajudavam os outros na preparação da aula e, também, no momento em que estavam sendo gravados, por meio de olhares de aprovação e de contribuições importantes na discussão proposta pelo futuro professor que estava coordenando a atividade. Compreendemos que essas atitudes não se assemelham ao que ocorre em uma sala de aula efetivamente, nem poderiam, pois os alunos que lá se encontram nunca tiveram o conteúdo, além de terem interesses diferentes.

Independente das limitações observadas na vivência da atividade, percebemos que a possibilidade de se ver como professor, ministrando um conteúdo, proporcionou outros conhecimentos relevantes à formação. A expressão de curiosidade nos licenciandos, que queriam logo após o encerramento da sua aula o arquivo com a gravação para olharem em casa, demonstrou o entusiasmo e o comprometimento com os objetivos do trabalho.

Além das contribuições formativas relatadas por meio da vivência da atividade, destacamos a escrita no diário de uma licencianda, que evidencia saberes docentes que estão sendo construídos por ela e que se caracterizam como aspectos significativos para a formação docente. Na escrita há aspectos significativos que trazemos para a discussão, sendo eles: a compreensão dos saberes necessários à docência, a constituição do professor reflexivo, o desenvolvimento da profissionalidade docente 
e o papel da escrita reflexiva no diário de bordo. Quanto a isso, concordamos com Alves, Pereira e Cabral (2013, p. 2), ao afirmarem que:

A prática docente deve ser marcada pelo processo de reflexão e renovação de seus instrumentos e estratégias metodológicas, buscando-se melhorar o sistema de ensino contemporâneo, que tem apresentado fragilidades multifatoriais, como por exemplo, o insucesso de algumas posturas didáticas tradicionais, sendo estas identificadas e discutidas cotidianamente no âmbito escolar.

Acerca dos saberes necessários para o trabalho do professor em sala de aula, temos nos apropriado do que propõe Shulman (1986). O autor nos apresenta o "conhecimento base" como alicerce do trabalho docente e propõe que,

[...] a base de conhecimentos para o ensino de um professor engloba sete conhecimentos, incluindo os três conhecimentos relacionados ao conteúdo específico a saber: Conhecimento do Conteúdo; Conhecimento do Currículo; Conhecimento Pedagógico do Conteúdo; Conhecimento Pedagógico Geral; Conhecimento dos Alunos e de suas características; Conhecimento dos Contextos; Conhecimento dos Objetivos, finalidades e valores educacionais, e de seus fundamentos filosóficos e históricos (SHULMAN, 1986, p. 10).

O conhecimento do conteúdo trata de uma compreensão profunda e o domínio da matéria a ensinar, o que diz respeito aos conceitos e temas que a constituem. Nesse sentido, na escrita realizada após a participação na atividade de simulação, a licencianda destaca que aprendeu muitas coisas para fazer o planejamento, e afirma que a História da Constituição da Matéria não é algo que se aprende em um ponto de ônibus com amigos em uma conversa informal, é um conteúdo específico que requer conhecimentos científicos que envolveram anos de estudos dos cientistas. Com isso, evidencia entendimentos acerca do conhecimento do conteúdo proposto por Shulman (1986). E L1 continua: precisei pensar em tudo o que ia falar com muito cuidado, para que não passasse para os alunos alguma informação equivocada.

Ainda, é possível acenar a compreensão da licencianda quanto ao conhecimento pedagógico do conteúdo, também apresentado por Shulman (1986). Segundo o autor, este conhecimento consiste nos modos de apresentar o conteúdo aos alunos, as estratégias escolhidas que possam contribuir para que o aluno aprenda. Quanto a isso, L1 destaca que sempre há o que se pode ser melhorado, e continua, destaco a importância de práticas como esta, para mostrar o que pode ser melhorado e tirar um pouco da insegurança referente à educação básica. Com isso, a licencianda evidencia a flexibilização do planejamento, que pode ter estratégias de ensino sempre 
repensadas. Os saberes demonstrados por L1 acenam para o potencial da atividade de simulação realizada, por meio das contribuições que a vivência, oportunizada na construção do plano de ensino e na sua execução em sala de aula, tiveram na formação inicial da futura professora.

A atividade de simulação tornou-se uma oportunidade de os futuros professores reconhecerem o papel docente por meio da aula dada por um dos colegas. Considerando que todos participaram das aulas gravadas, no papel de alunos, com isso, puderam desenvolver um olhar para a atuação docente do outro. A compreensão do trabalho docente como ação coletiva é proposta por Zeichner (1995, p. 120), que defende a "perspectiva reconstrucionista social da prática reflexiva". Para o autor, a ação docente se constitui coletivamente, pois sozinhos não vamos encontrar respostas aos problemas da prática.

Nesse sentido, em nossos estudos, temos observado o isolamento como um dos principais problemas vivenciados pelos professores que atuam na Educação Básica, que pode se tornar um fator limitante ao desenvolvimento profissional docente e, ainda, promover complicações nos processos de ensinar e aprender em sala de aula. Quanto a isso, Finger e Bedin (2019, p. 11) defendem que:

[...] é de imensurável importância que o docente admita com seriedade o compromisso de instigar o aluno em sala de aula, despertando a sua curiosidade e o seu interesse por meio da contextualização dos saberes científicos a partir da sua realidade de vida.

A atividade de simulação realizada no processo de formação inicial tornou-se uma oportunidade de desenvolver a reflexão coletivamente. Mesmo que a análise empreendida por cada licenciando tenha sido individual, não podemos deixar de destacar a importância do contexto em que a atividade transcorreu: trata da sala de aula em que colegas, da futura profissão, compartilham o dia a dia de aprendizagens sobre a docência. Assim, a possibilidade de ver o outro, um colega, em ação pode contribuir com o processo formativo coletivo por meio da solidariedade, pois, de acordo com Zeichner (2008, p. 535), "ser desafiado e, ao mesmo tempo, apoiado por meio da interação social é importante para ajudar-nos a clarificar aquilo que nós acreditamos e para ganharmos coragem para perseguir nossas crenças”.

No processo realizado na aula de metodologia, identificamos aspectos significativos à formação de todos, o desenvolvimento do espírito colaborativo em cada licenciando, que, conforme Alarcão (2005, p. 34), "não se desenvolve através de 
monólogos expositivos". Para a autora, "o desenvolvimento do espírito crítico faz-se no diálogo, no confronto de ideias e de práticas, na capacidade de se ouvir o outro, mas também de se ouvir a si próprio e de se autocriticar" (ALARCÃO, 2005, p. 34).

Durante as gravações, observamos o carinho de uns para com os outros, evidenciado nas ações realizadas. Quando uma atividade parecia não estar dando muito certo, tinha sempre um colega que fazia alguma contribuição, seja por meio de uma pergunta para auxiliar o professor ou, ainda, auxiliando na realização da parte experimental. Percebemos que o fato de estarem juntos na sala, mesmo em funções diferentes, possibilitou uma atmosfera de confiança entre todos, pois quem estava conduzindo a aula demonstrava segurança com relação à participação da turma e nervosismo apenas com relação ao processo de gravação.

A escrita da licencianda no diário de bordo, sobre as aulas dadas pelos colegas, demonstra, ainda, a formação do profissional reflexivo, conforme apresentado por Alarcão (2005). Para a autora, "A noção de professor reflexivo baseia-se na consciência da capacidade de pensamento e reflexão que caracteriza o ser humano como criativo e não como mero reprodutor de ideias e práticas que lhe são exteriores" (ALARCÃO, 2005, p. 44). Assim, acenamos que, por meio da atividade de simulação, a licencianda desenvolveu consciência da sua identidade profissional, o que é muito significativo quando realizado ainda no processo de formação inicial.

Ao afirmar que vi realmente um(a) professor(a), a licencianda demonstra a importância do trabalho para a construção da profissionalidade docente por meio do desenvolvimento do professor reflexivo, conforme apresenta Alarcão (2005). Para a autora, "a noção de professor reflexivo baseia-se na consciência da capacidade de pensamento e reflexão que caracteriza o ser humano como criativo e não como mero reprodutor de ideias e práticas que lhe são exteriores" (ALARCÃO, 2005, p. 54).

Ainda, destacamos que a compreensão da futura professora quanto aos aspectos que contribuíram para identificar o ser professor nos colegas, e, em si, somente foi possível pela vivência proporcionada na simulação, pois conforme Schön (1995, p. 85), "só se pode ter uma nova perspectiva sobre alguma coisa após nos termos afastado dela". Nesse sentido, a atividade de simulação tornou-se um instrumento potencializador da reflexão, pois a gravação das ações realizadas possibilitou que cada licenciando observasse a atuação por várias vezes e, com isso, pudesse refletir de forma diferente em cada observação. 
No relato, a licencianda destaca várias características fundamentais para 0 trabalho docente, que observou no processo de simulação, entre as quais cita a segurança dos colegas, o domínio do conteúdo e as situações inesperadas que precisam ser resolvidas no momento da aula. As observações compartilhadas por ela evidenciam o desenvolvimento do professor reflexivo, conforme apresentado, também, por Schön (1995), ainda em processo de formação inicial. Para Schön (1995, p. 83), o processo de reflexão-na-ação pode ser desenvolvido em vários momentos "sutilmente combinados numa habilidosa prática de ensino".

Ressaltamos que o processo de simulação não é completamente eficaz ao limitar o desenvolvimento de entendimento com relação ao processo de aprender dos alunos, apenas com o processo de ensinar do professor, visto que os alunos que estavam participando da atividade eram colegas já em outros momentos. Porém, é válido destacar a busca por outras ferramentas, ficando claro que cada licenciando buscou a forma de dar aula que lhe cabia mais conforto e segurança, pois, de acordo com Vygotsky (2000), a aprendizagem só é significativa quando os alunos conseguem internalizar o novo conceito de forma a operar com ele em diferentes situações, que passe a fazer parte de sua visão de mundo, ou seja, relacionar os conceitos trabalhados em sala de aula com situações vividas em seus contextos.

Destacamos, também, que alguns dos licenciandos, participantes da atividade, vivenciam experiências em escolas de Educação Básica por meio de programas de iniciação à docência como, por exemplo, PETCiências. Com isso, observamos nesses licenciandos maior facilidade na realização do processo, pois possuem conhecimento acerca do ambiente escolar no desenvolvimento de atividades práticas, ajudando a manter a calma, ocupar bem o espaço, as ferramentas e o tempo.

Destarte, foram várias as contribuições da atividade de simulação no processo de formação inicial de professores. Identificamos conhecimentos desenvolvidos durante o processo que podem contribuir na constituição docente, entre os quais destacamos o conhecimento pedagógico de conteúdo. Não obstante, reconhecemos que o processo possui limitações quanto à realidade escolar, porém trata de uma atividade potencializadora da formação, pois possibilita uma vivência próxima da realidade. 


\section{Considerações finais}

No presente relato, buscamos compartilhar aspectos significativos à formação de professores de Ciências e de Química evidenciados na realização de uma atividade de simulação de sala de aula. Salientamos o potencial da atividade, que se desenvolveu pelo compromisso coletivo de um grupo de futuros professores, que se colocaram à disposição de terem aulas gravadas para posterior análise individual. A análise das possibilidades formativas da atividade foi identificada nas escritas reflexivas dos licenciandos nos diários de bordo e na vivência observada no momento da gravação.

Com a participação efetiva dos licenciandos da turma nos momentos de organização e realização da atividade, podemos afirmar que as contribuições ocorreram tanto aos futuros professores como para a professora formadora. A possibilidade de se ver como professor desencadeou outro olhar nos licenciandos, uma nova perspectiva da profissão docente. Nas escritas nos diários de bordo destacam-se aspectos significativos, entre os quais compartilhamos as escritas de uma licencianda, participante de todos os momentos e discussões. Os relatos no diário de bordo acenam para o desenvolvimento de entendimentos acerca dos conhecimentos necessários ao professor, que não são apenas acerca do conteúdo, mas de como trabalhar determinados conceitos em sala de aula de modo que o aluno aprenda.

Ainda, ressaltamos que a realização da atividade proporcionou observar características individuais de cada licenciando, que podem contribuir para o papel da professora formadora como orientadora de estágios. Ao perceber limitações nas ações dos licenciandos, a professora pode buscar estratégias que possam auxiliar cada um individualmente na superação dos problemas que se tornaram evidentes na realização da simulação da aula.

Compreendemos que, ao refletirmos, tomamos consciência das ações empreendidas. Assim, podemos afirmar, por meio da leitura das reflexões de uma licencianda, que, como participante da atividade, ela desenvolveu novos entendimentos acerca da sua formação e da formação dos próprios colegas, o que foi oportunizado pela atividade de simulação. A licencianda demonstra compreender a importância do conhecimento pedagógico de conteúdo e a importância em avaliar-se permanentemente. Ainda, busca identificar aspectos formativos nos outros destacando características como dedicação e insegurança, e, ainda, evidencia que a atividade de simulação contribui para o processo de reflexão da prática docente. 
Destarte, defendemos que a estratégia utilizada no componente curricular de prática de ensino pode ser replicado em outros componentes de prática, pois compreendemos que, a cada nova aula oportunizada aos licenciandos para que ministrem, ainda no processo de formação inicial, novas possibilidades formativas vão surgir e, com isso, qualificar cada vez mais o processo formativo.

Portanto, a busca por atividades que contribuam para qualificar o processo formativo, tem sido nosso principal objetivo, considerando nosso envolvimento com a formação inicial de professores. Nesse sentido, reforçamos a importância da atividade de simulação de aula como um importante instrumento que desenvolve nos futuros professores novas perspectivas acerca do trabalho docente tornando a vivência em sala de aula uma experiência marcante para o seu futuro.

\section{3,2,1 recording! and now? simulation of class in the process of initial training of chemistry teachers}

\section{Abstract}

Teaching practices are mandatory curriculum components in undergraduate courses in Brazil and have been the object of study over the last few years seeking to qualify the processes of teacher education. With the objective of investigating the contributions of a different methodology carried out in teaching practice classes, developed in a degree course in Chemistry of a public university, this study was carried out, which presents the formative possibilities of a class simulation activity. The simulation activity was intended to provide future teachers with real experiences of classroom experience prior to the completion of the curricular internship and also the understanding of the challenges and possibilities of teaching planning and classroom execution. Through the report of a graduate student participating in the activity, and your logbook, an instrument used as a record of personal reflection, we identified the development of understandings about the real characteristics of the classroom, such as class time, teacher-student interaction and the experience of unexpected teaching situations. It is noteworthy that the lived experience, through the class simulation process, qualified the formative process through the development of experiential knowledge.

Keywords: Teaching experience. Initial formation. Teaching Practice.

\section{Referências}

ALARCÃO, I. Professores reflexivos em uma escola reflexiva. São Paulo: Cortez, 2005.

ALVES, T. L. B. PEREIRA, S. S. CABRAL, L. N. A utilização de charges e tiras humorísticas como recurso didático-pedagógico mobilizador no processo de ensino-aprendizagem da Geografia. 2013. Disponível em: <https://periodicos.ufsm.br/reveducacao/article/view/7915>. Acesso em: 10 de agosto de 2019. 
BRASIL. Conselho Nacional de Educação. Define as Diretrizes Curriculares Nacionais para a formação inicial em nível superior (cursos de licenciatura, cursos de formação pedagógica para graduados e cursos de segunda licenciatura) e para a formação continuada. Resolução CNE/CP n. 02/2015, de $1^{\circ}$ de julho de 2015. Brasília, Diário Oficial [da] República Federativa do Brasil, seção 1, n. 124, p. 8-12, 02 de julho de 2015. Disponível em: $<$ http://pesquisa.in.gov.br/imprensa/jsp/visualiza/index.jsp?data=02/07/2015\&jornal=1\& pagina $=8 \&$ totalArquivos $=72>$.

FINGER, I.; BEDIN, E. A contextualização e seus impactos nos processos de ensino e aprendizagem da ciência química. Revista Brasileira de Ensino de Ciências e Matemática, v. 2, n. 1, p. 8-24, 16 ago. 2019.

LARROSA, J. B. Notas sobre a experiência e o saber de experiência. Revista brasileira de educação, n. 19, 2002.

MALDANER, O. A. A formação inicial e continuada de professores de química: Professores/ Pesquisadores. 2. Ed. Ijuí: Ed. Unijuí, 2003.

NÓVOA, A. Formação de Professores e profissão docente. In: Os professores e a sua Formação. Os professores e sua formação. Lisboa: Dom Quixote. 2 ed. p. 15-33, 1995.

PORLÁN, R.; MARTÍN, J. El diario del profesor. Sevilla: Díada Editora, 1997.

SCHÖN, D. Formar professores como profissionais reflexivos. In A. Nóvoa (Ed.), Os professores e a sua formação (pp. 79-91). Lisboa, D. Quixote, 1995.

SHULMAN, L. S. Those who understand: Knowledge growth in teaching. Educational researcher, v. 15, n. 2, p. 4-14, 1986.

UNIVERSIDADE FEDERAL DA FRONTEIRA SUL. Plano Pedagógico do Curso de Química Licenciatura. Novembro/2012. Disponível em: <http:/www.uffs.edu.br/images/DOP/Quimica_C_Largo_2013.pdf> Acesso em: 22 jan. 2019.

VYGOTSKI, L. S. A Construção do Pensamento e da Linguagem. Trad. Paulo Bezerra, 1 ed. São Paulo: Martins Fontes, 2000, 296 p.

ZEICHNER, K. A formação reflexiva de professores: Ideias e práticas. Lisboa: Educa, 1993.

ZEICHNER, K. Novos Caminhos para o practicum: uma perspectiva para os anos 90. In A. Nóvoa (Ed.), Os professores e a sua formação (pp. 79-91). Lisboa, D. Quixote, 1995.

ZEICHNER, K. Uma análise crítica sobre a "reflexão" como conceito estruturante na formação docente. Educ. Soc., Campinas, v. 29, n. 103, p. 535-554, maio/ago. 2008. Disponível em: <http://www.cedes.unicamp.br>. Acesso em: 13 set. 2019. 